\title{
Polyphosphate adsorption and hydrolysis on aluminum oxides
}

\author{
Biao Wan ${ }^{1}$, Rixiang Huang ${ }^{1}$, Julia M. Diaz ${ }^{2}$, Yuanzhi Tang ${ }^{1 *}$ \\ ${ }^{1}$ School of Earth and Atmospheric Sciences, Georgia Institute of Technology, 311 Ferst Drive, \\ Atlanta, GA 30332-0340, USA \\ ${ }^{2}$ Skidaway Institute of Oceanography, Department of Marine Sciences, University of Georgia, \\ Savannah, GA, USA
}

*Corresponding author. Email: yuanzhi.tang@eas.gatech.edu; Phone: 404-894-3814

Total 23 pages

16 figures

2 tables 


\section{Text S1. Characterization of $\gamma-\mathrm{Al}_{2} \mathrm{O}_{3}$ samples}

$\gamma-\mathrm{Al}_{2} \mathrm{O}_{3}$ samples of three different particle sizes $(5,35$, and $70 \mathrm{~nm})$ were characterized by powder X-ray diffraction (XRD), transmission electron microscopy (TEM), and $\mathrm{N}_{2}$ gas adsorptiondesorption BET (measured at $77 \mathrm{~K}$ ). TEM images confirmed that the average particle diameters were around 5, 35 and $70 \mathrm{~nm}$, respectively (Fig. S1). The particles of the 5 and $35 \mathrm{~nm} \gamma-\mathrm{Al}_{2} \mathrm{O}_{3}$ samples were needle shaped, while the particles of the $70 \mathrm{~nm}$ sample appear to be rhombohedral. Their powder XRD patterns indicated increasing crystallinity with increasing particle size, and the $35 \mathrm{~nm}$ sample contained some small amount of $\alpha-\mathrm{Al}_{2} \mathrm{O}_{3}$ (Fig. S2). BET specific surface areas (SSA) of the 5, 35, and $70 \mathrm{~nm}$ samples were 325,167 , and $126 \mathrm{~m}^{2} \mathrm{~g}^{-1}$, respectively, consistent with the increasing particle size. More detailed characterization information can be found in previous study. ${ }^{1}$ Compared to environmental $\mathrm{Al}$ oxide minerals (e.g., corundum, boehmite, gibbsite and bayerite), $\gamma-\mathrm{Al}_{2} \mathrm{O}_{3}$ has larger surface area and higher reactivity for $\mathrm{P}$ adsorption. ${ }^{1,2}$ The point of zero charge (PZC) values of amorphous $\mathrm{Al}(\mathrm{OH})_{3}$, boehmite, corundum, and gibbsite were reported to be 9.3, 9.2, 8.9 and 8.6, respectively. ${ }^{2-4}$ The PZC values of 5, 35, and $70 \mathrm{~nm} \gamma-\mathrm{Al}_{2} \mathrm{O}_{3}$ were reported to be $9.3,9.1$ and 8.5 , respectively ${ }^{1}$, and are similar to those of the environmentally relevant $\mathrm{Al}$ oxide minerals. Previous studies have also shown that hydration at $\mathrm{pH}>5$ can slowly transform $\gamma-\mathrm{Al}_{2} \mathrm{O}_{3}$ to gibbsite and/or bayerite. ${ }^{5}$ The short hydration time employed in this study (overnight) might lead to minor transformation of the surface of $\gamma-\mathrm{Al}_{2} \mathrm{O}_{3}$ particles, but was not detected by XRD in our preliminary studies.

\section{Text S2. Characterization of the Na-polyphosphate salt}

The average chain length of the polyphosphate samples were calculated based on the ratio of the peak area between the end groups and middle groups in polyphosphate solution ${ }^{31} \mathrm{P}$ nuclear magnetic resonance (NMR) spectrum. ${ }^{6}$ Quantitative analyses of the ${ }^{31} \mathrm{P}$ NMR spectra of the Napolyphosphate (Na-polyP) salt (Fig. S3) indicated an average chain length of 10 using this NMR method. Thus, the molecular formula of this sample can be defined as $\mathrm{Na}_{12} \mathrm{P}_{10} \mathrm{O}_{31}$.

\section{Text S3. NMR data collection and analysis}

After 9-day reaction, the reaction suspensions were centrifuged to separate the solid and supernatant. The supernatant samples were directly used for solution ${ }^{31} \mathrm{P}$ NMR spectroscopy analysis. The wet pastes were freeze-dried for analysis of solid state ${ }^{31} \mathrm{P}$ NMR spectroscopy.

Solution ${ }^{31} P$ NMR spectra were collected on a Bruker AMX $400 \mathrm{MHz}$ spectrometer operated at $162 \mathrm{MHz}$ and $297 \mathrm{~K}$. A $90^{\circ}$ pulse width, $6.5 \mathrm{k}$ data points (TD) over an acquisition time of $0.51 \mathrm{~s}$, and relaxation delay of $2 \mathrm{~s}$ were applied. Chemical shift was calibrated using $85 \% \mathrm{H}_{3} \mathrm{PO}_{4}$ as the external standard. At least 1500 scans were collected for each spectrum $(>2 \mathrm{~h})$.

Solid-state ${ }^{31} \boldsymbol{P}$ NMR spectra were acquired using single pulse/magic angle spinning (SP/MAS) and proton decoupling on a Bruker Avance 400 spectrometer operated at a ${ }^{31} \mathrm{P}$ frequency of $161.9 \mathrm{MHz}$. Solid samples $(\sim 20 \mathrm{mg})$ were packed into the inserts of a $4 \mathrm{~mm}$ diameter zirconia rotor with Kel-F Caps (Wilmad, NJ) and spun at $10 \mathrm{kHz}$. Direct polarization (DP) data collection parameters were 2048 data points (TD) over an acquisition time (AQ) of $24.6 \mathrm{~ms}$, a recycle delay (RD) of $180 \mathrm{~s}$, and 256 scans. Variable RD experiments were conducted and $180 \mathrm{~s}$ were verified to be sufficient to prevent signal saturation during data acquisition. The DP-MAS ${ }^{31} \mathrm{P}$ NMR spectra were acquired with a ${ }^{31} \mathrm{P} 90^{\circ}$ pulse of $5.0 \mu$ s and an attenuation level (PL1) of 12.1 dB. Chemical shifts were externally referenced to $\mathrm{NH}_{4} \mathrm{H}_{2} \mathrm{PO}_{4}$ at $0.72 \mathrm{ppm}$. ${ }^{31} \mathrm{P}$ spin counting 
experiments were based on previous reports where $\mathrm{NH}_{4} \mathrm{H}_{2} \mathrm{PO}_{4}$ was used as an external intensity standard and its ${ }^{31} \mathrm{P}$ DP NMR spectrum was acquired in one scan after equilibration for $1000 \mathrm{~s}$ (16.7 min). ${ }^{41} \mathrm{P}\left\{{ }^{1} \mathrm{H}\right\}$ Cross-polarization (CP)/MAS spectra were also collected for those samples. The CP contact time was set at $1 \mathrm{~ms}$ and 256 scans were collected for samples. CP kinetics curves were measured at a spinning rate of $10 \mathrm{kHz}$ with continuous wave $(\mathrm{CW})$ irradiation at the $\mathrm{n}=-1$ sideband match condition, varying the contact time from 0.3 to $7 \mathrm{~ms}$. Proton decoupling was employed during acquisition of all ${ }^{31} \mathrm{P}\left\{{ }^{1} \mathrm{H}\right\}$ CP/MAS spectra.

The SP/MAS ${ }^{31} \mathrm{P}$ NMR spectra were deconvoluted into component resonance lines using Origin 2016. The resonance line shape chosen was 100\% Gaussian. All spectra were deconvoluted into three resonance lines with fixed peak positions based on our assignments for surface $\mathrm{P}$ species on $\gamma-\mathrm{Al}_{2} \mathrm{O}_{3}$ in Section 3.3, including 1) calcium phosphate precipitates, 2) phosphate groups in polypohosphate that are complexed on the mineral surfaces as inner-sphere species (to polyP$\mathrm{P}_{\text {bonded}}$ ), and 3) phosphate group in polyphosphate that are not associated with the mineral surface (to polyP-P $\mathrm{P}_{\text {unonded }}$ ). We did not observe the chemical shift for orthophosphate (produced from polyphosphate hydrolysis) adsorption on $\gamma-\mathrm{Al}_{2} \mathrm{O}_{3}$, possibly due to the strong competitive adsorption between orthophosphate and residual polyphosphate or low surface coverage of orthophosphate on $\gamma-\mathrm{Al}_{2} \mathrm{O}_{3}$ surface (if any). Therefore, we did not include adsorbed orthophosphate species during peak deconvolution of surface $\mathrm{P}$ speciation.

Two-dimensional (2D) $\left.{ }^{31} \mathrm{P}^{1} \mathrm{H}\right\}$ heteronuclear correlation (HetCor) spectra were collected to obtain ${ }^{1} \mathrm{H}$ spectra indirectly. The HetCor experiments employed a spinning rate of 12 $\mathrm{kHz}$ and a CP contact time of $3 \mathrm{~ms}$, using a linear ramp of the ${ }^{31} \mathrm{P} \mathrm{B} 1$ field and $42 \mathrm{kHz}{ }^{1} \mathrm{H}$ field. We collected 150 hypercomplex points in $\mathrm{t} 1$ with a $10 \mu$ s increment, corresponding to a $100 \mathrm{kHz}$ spectral window in F1. For spectra containing narrow ${ }^{1} \mathrm{H}$ peaks, standard linear prediction methods were used to complete the signal decay in F1 to avoid truncation artifacts. For each spectrum, 48 scans were collected for each point at a $1 \mathrm{~s}$ relaxation delay. The spectra were acquired in ${ }^{1} \mathrm{H}-$ coupled mode, with no homonuclear ${ }^{1} \mathrm{H}$ decoupling pulses applied during $\mathrm{t}$. The ${ }^{1} \mathrm{H}$ NMR chemical shifts $\left(\delta_{\mathrm{H}}\right)$ are referenced with respect to tetramethylsilane (TMS) using adamantane as a secondary reference set to $\delta_{\mathrm{H}}=2.0 \mathrm{ppm}$.

Solid-state SP/MAS ${ }^{27} \mathbf{A l}$ NMR spectra of $\gamma-\mathrm{Al}_{2} \mathrm{O}_{3}$ loaded with polyphosphate and standard samples (aluminum polyphosphate) were collected on a Bruker Avance 400 spectrometer operated at a ${ }^{27} \mathrm{Al}$ frequency of $104.2 \mathrm{MHz}$, with samples contained in $4 \mathrm{~mm}$ (o.d.) $\mathrm{ZrO}_{2}$ rotors at a spinning rate of $10 \mathrm{kHz}$. The ${ }^{27} \mathrm{Al}$ chemical shifts $\left(\delta_{\mathrm{Al}}\right)$ are reported relative to an external $1 \mathrm{M} \mathrm{Al}\left(\mathrm{NO}_{3}\right)_{3}$ solution set to $\delta^{\mathrm{Al}}=0 \mathrm{ppm}$. The pulse delay was optimized at $5 \mathrm{~s}$, and approximately 128 (Experiment Set I) or 1024 (Experiment Set II) scans were collected for spectra to obtain an acceptable signal-to-noise ratio.

\section{Text S4. CP/MAS spectra kinetics}

The signal intensity and area varies with $\mathrm{CP}$ contact time (s) according to the classical biexponential equation.

$$
I(\tau)=I_{0}\left[1-\frac{T_{P H}}{T_{1 \rho, H}}\right]^{-1}\left[\exp \left(-\frac{\tau}{T_{1 \rho, H}}\right)-\exp \left(-\frac{\tau}{T_{P H}}\right)\right]
$$


Where $T_{P H}$ is the characteristic time for ${ }^{1} \mathrm{H} \rightarrow{ }^{31} \mathrm{P}$ magnetization transfer and $T_{1 \rho, H}$ is the time constant for decay of the ${ }^{1} \mathrm{H}$ magnetization in the rotating frame. ${ }^{7}$ Typical $\mathrm{CP}$ kinetic curves were shown in Fig. S11, along with least-square fits to Eq. (1), which illustrated the effects of CP contact time on the peak areas. The peak areas of varied $\mathrm{P}$ species in these three samples built up polarization quickly, reached a maximum area around $1 \mathrm{~ms}$ contact time, and then declined sharply with further increase in contact time (Fig. S11).

\section{Text S5. P K-edge XANES data collection and analysis}

Freeze-dried samples after reaction were analyzed by P K-edge XANES at Beamline 14-3 at the Stanford Synchrotron Radiation Lightsource (SSRL), Menlo Park, CA. Sample powders were brushed evenly onto P-free Kapton tape and mounted to a sample holder maintained under helium atmosphere. XANES data were collected in fluorescence mode using a PIPS detector. Energy calibration used $\mathrm{AlPO}_{4}$ (edge position at $2152.8 \mathrm{eV}$ ). XANES spectra were collected at $2100-2485 \mathrm{eV}$.

Additionally, a suite of P reference compounds were prepared for XANES analysis: (1) polyphosphate sodium salt (Na-polyP) (Sigma Aldrich) and synthetic Ca-polyP granules (synthesized via 1:1 mixture of $10 \mathrm{mM} \mathrm{Ca}^{2+}$ and polyphosphate at total $\mathrm{P}$ concentration of $10 \mathrm{mM}$ at $\mathrm{pH}$ 7.0. The same mothed was used to synthesize Al-polyP), representing solid polyphosphate phases; (2) orthophosphate sorbed on $\gamma-\mathrm{Al}_{2} \mathrm{O}$, prepared at $\mathrm{pH} 6.0$ following previous method ${ }^{1}$ and was centrifuged after 6-h adsorption reaction time, representing Al oxide associated orthoP; (3) polyphosphate sorbed on $\gamma-\mathrm{Al}_{2} \mathrm{O}_{3}$, prepared at $\mathrm{pH} 6.0$ using the same way for orthophosphate sorbed samples, representing Al oxide associated polyP; (4) amorphous calcium phosphate (ACP), octacalcium phosphate (octaCa), and hydroxyapatite, ${ }^{8}$ representing calcium phosphate precipitates. XANES spectra of all reference compounds were collected in the same manner as for unknown samples.

Data analysis used the software Ifeffit. ${ }^{9}$ All spectra were carefully examined for energy calibration, merged, and normalized. Linear combination fitting (LCF) was conducted on the XANES spectra at energy range of 15 to $50 \mathrm{eV}$ relative to the edge energy. The goodness of fit was evaluated using the residual factor (R-factor), and fit with smallest R-factor was decided as the best fit. 
Table S1. Experimental design and reaction conditions.

\begin{tabular}{|c|c|c|c|c|c|c|}
\hline $\begin{array}{l}\text { Experiment } \\
\text { Set }\end{array}$ & $\begin{array}{c}\text { Experiment } \\
\#\end{array}$ & $\begin{array}{c}\text { PolyP } \\
\text { concentration } \\
(\text { as total P) }\end{array}$ & $\begin{array}{c}\mathrm{Y}-\mathrm{Al}_{2} \mathrm{O}_{3} \\
\text { particle } \\
\text { size }\end{array}$ & $\begin{array}{c}\mathrm{V}-\mathrm{Al}_{2} \mathrm{O}_{3} \\
\text { concentration }\end{array}$ & $\mathrm{pH}$ & $\begin{array}{l}\text { Metal cation } \\
\text { and } \\
\text { concentration }\end{array}$ \\
\hline \multirow[t]{2}{*}{ Set I } & $\mathrm{I}-1$ & $2 \mathrm{mM}$ & $\begin{array}{c}5,35,70 \\
n m\end{array}$ & $0.4 \mathrm{~g} / \mathrm{L}$ & $6.0,8.0$ & - \\
\hline & $\mathrm{I}-2$ & $2 \mathrm{mM}$ & $\begin{array}{c}5,35,70 \\
\mathrm{~nm}\end{array}$ & $0.4 \mathrm{~g} / \mathrm{L}$ & $6.0,8.0$ & $\mathrm{Ca}^{2+}(1 \mathrm{mM})$ \\
\hline \multirow{2}{*}{ Set II } & II-1 & $1 \mathrm{mM}$ & $5 \mathrm{~nm}$ & $0.1 \mathrm{~g} / \mathrm{L}$ & 6.0 & $\begin{array}{c}\mathrm{Ca}^{2+}, \mathrm{Mg}^{2+} \\
\mathrm{Cu}^{2+}, \mathrm{Mn}^{2+} \\
\mathrm{Zn}^{2+}(0.5 \mathrm{mM})\end{array}$ \\
\hline & II-2 & $1 \mathrm{mM}$ & $5 \mathrm{~nm}$ & $0.1 \mathrm{~g} / \mathrm{L}$ & 8.0 & $\begin{array}{c}\mathrm{Ca}^{2+}, \mathrm{Mg}^{2+} \\
\mathrm{Cu}^{2+}, \mathrm{Mn}^{2+} \\
\mathrm{Zn}^{2+}(0.5 \mathrm{mM})\end{array}$ \\
\hline
\end{tabular}


Table S2. Relative percentage of orthophosphate and polyphosphate in solution calculated based on the NMR data in Fig. 2 and solution data in Figs. 1 and S3.

\begin{tabular}{|c|c|c|c|c|c|c|}
\hline $\begin{array}{c}\mathrm{Y}-\mathrm{Al}_{2} \mathrm{O}_{3} \\
\text { particle } \\
\mathbf{s i z e}(\mathbf{n m})\end{array}$ & \multirow{2}{*}{$\begin{array}{c}\mathbf{C a}^{2+} \\
(\mathbf{m M})\end{array}$} & $\mathbf{p H}$ & \multicolumn{2}{|c|}{ NMR analysis } & \multicolumn{2}{c|}{ Wet chemistry analysis } \\
\hline & & $\begin{array}{c}\text { Orthophosphate } \\
(\%)\end{array}$ & $\begin{array}{c}\text { Polyphosphate } \\
(\%)\end{array}$ & $\begin{array}{c}\text { Orthophosphate } \\
(\%)\end{array}$ & $\begin{array}{c}\text { Polyphosphate } \\
(\%)\end{array}$ \\
\hline 5 & - & 6 & 9.2 & 90.8 & 6.4 & 93.6 \\
\hline 35 & - & 6 & 8.29 & 91.71 & 5.44 & 94.56 \\
\hline 70 & - & 6 & 9.18 & 90.82 & 5.17 & 94.83 \\
\hline 5 & 1 & 6 & 29.94 & 70.06 & 19.33 & 80.67 \\
\hline 35 & 1 & 6 & 28.4 & 71.6 & 16.72 & 83.28 \\
\hline 70 & 1 & 6 & 26.08 & 73.92 & 15.19 & 84.81 \\
\hline 5 & - & 8 & 5.56 & 94.44 & 6.54 & 93.46 \\
\hline 35 & - & 8 & 6.25 & 93.75 & 4.93 & 95.07 \\
\hline 70 & - & 8 & 6.93 & 93.07 & 4.69 & 95.31 \\
\hline 5 & 1 & 8 & 55.54 & 44.46 & 47.49 & 52.51 \\
\hline 35 & 1 & 8 & 47.87 & 52.13 & 35.37 & 64.63 \\
\hline 70 & 1 & 8 & 40.87 & 59.13 & 26.78 & 73.22 \\
\hline
\end{tabular}



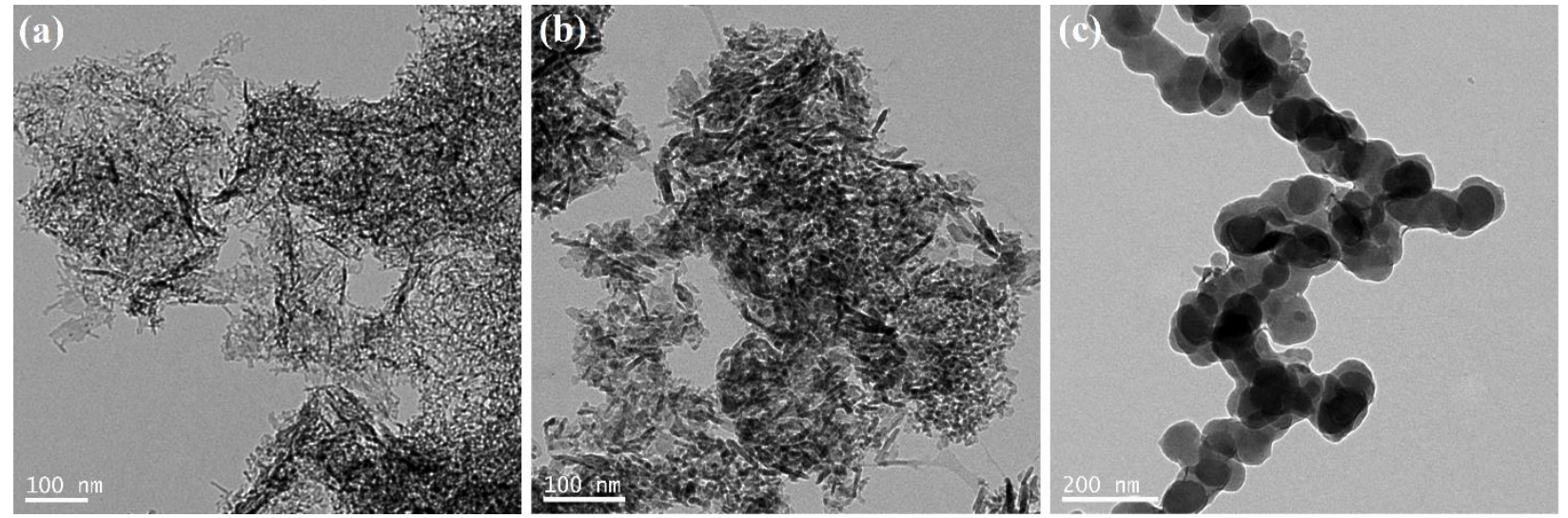

Fig. S1. Transmission electron microscope (TEM) images of $5 \mathrm{~nm}$ (a), $35 \mathrm{~nm}$ (b), and $70 \mathrm{~nm} \gamma$ $\mathrm{Al}_{2} \mathrm{O}_{3}$. Initial TEM images can be found in supplementary materials of the previous study. ${ }^{1}$ 


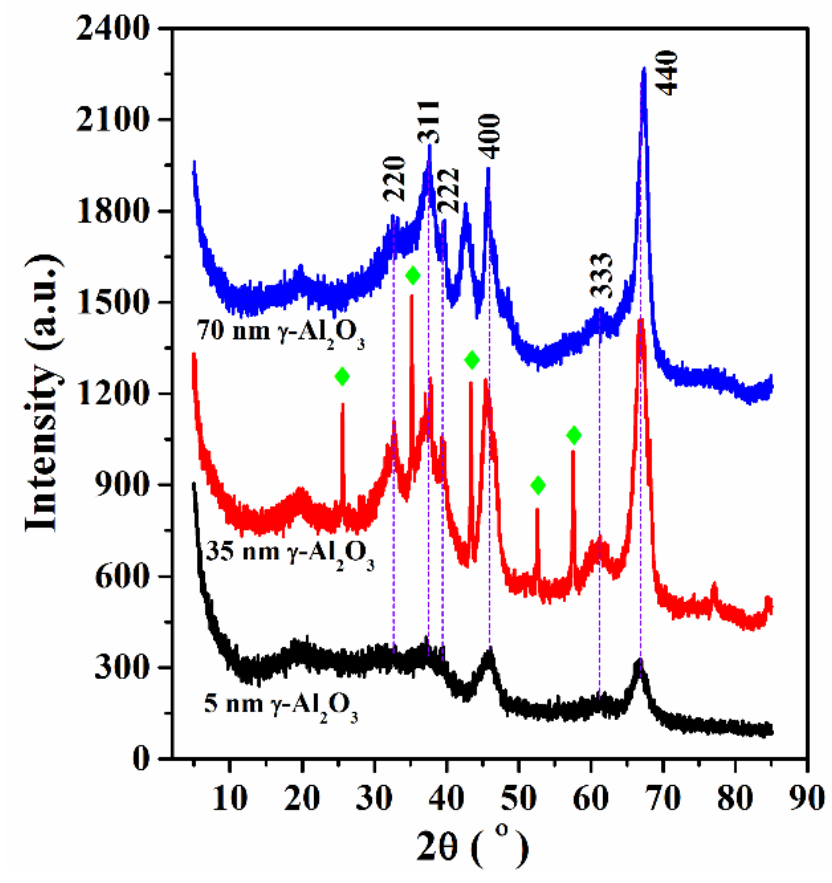

Fig. S2. X-ray diffraction (XRD) patterns of $\gamma-\mathrm{Al}_{2} \mathrm{O}_{3}$ with average 5, 35, and $70 \mathrm{~nm}$ particle sizes. Asterisks indicate the presence of small amount of $\alpha-\mathrm{Al}_{2} \mathrm{O}_{3}$ in the $35 \mathrm{~nm}$ sample. Initial XRD patterns can be found in supplementary materials of the previous study. ${ }^{1}$ 


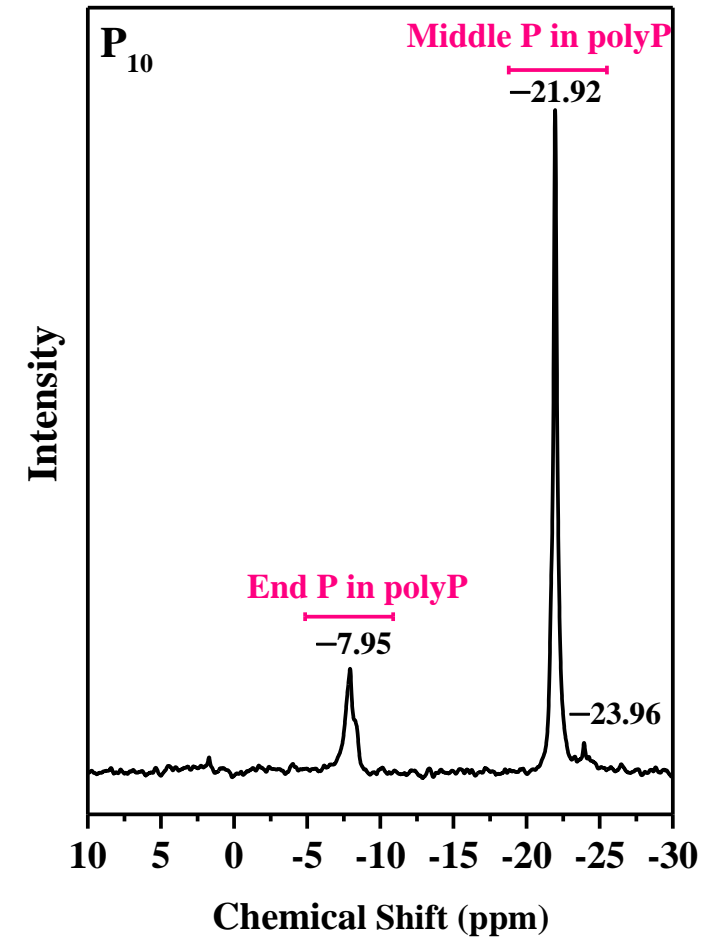

Fig. S3. ${ }^{31} \mathrm{P}$ solution NMR spectrum of polyphosphate stock solutions prepared from sodium polyphosphate salts in total $\mathrm{P}$ concentration of $40 \mathrm{mM}$. 

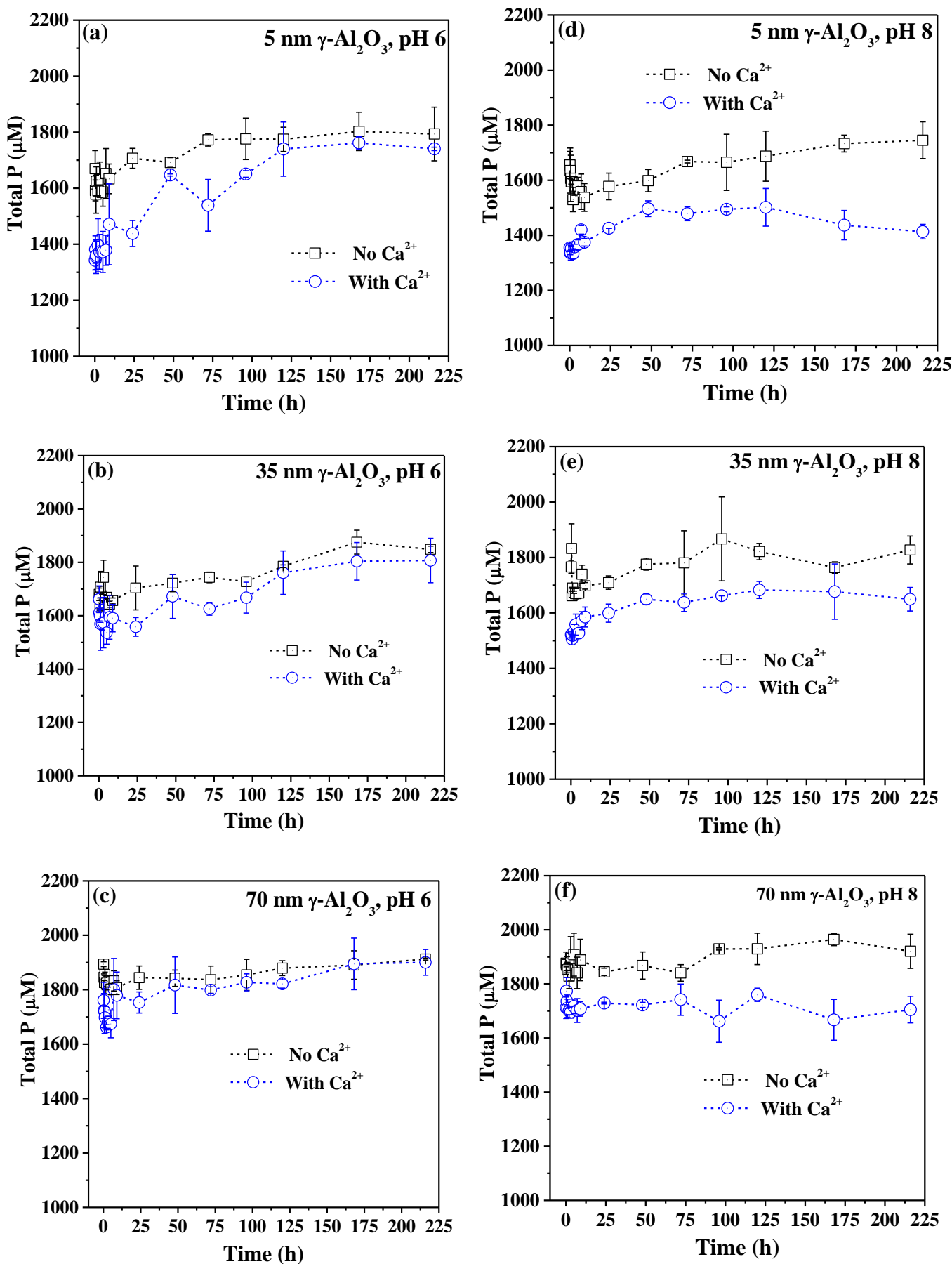

Fig. S4 Dynamic of dissolved total $\mathrm{P}$ concentration during hydrolysis of polyphosphate hydrolysis by $5 \mathrm{~nm}(\mathrm{a}, \mathrm{d}), 35 \mathrm{~nm}(\mathrm{~b}, \mathrm{e})$, and $70 \mathrm{~nm}(\mathrm{c}, \mathrm{f}) \gamma-\mathrm{Al}_{2} \mathrm{O}_{3}$ (Experiment Set I). Reaction condition: polyphosphate ( $2 \mathrm{mM}$ as total $\mathrm{P}$ ), $\gamma-\mathrm{Al}_{2} \mathrm{O}_{3} 0.4 \mathrm{~g} / \mathrm{L}, \mathrm{pH} 6.0$ and 8.0 , with/without $1 \mathrm{mM} \mathrm{Ca}^{2+}$. 

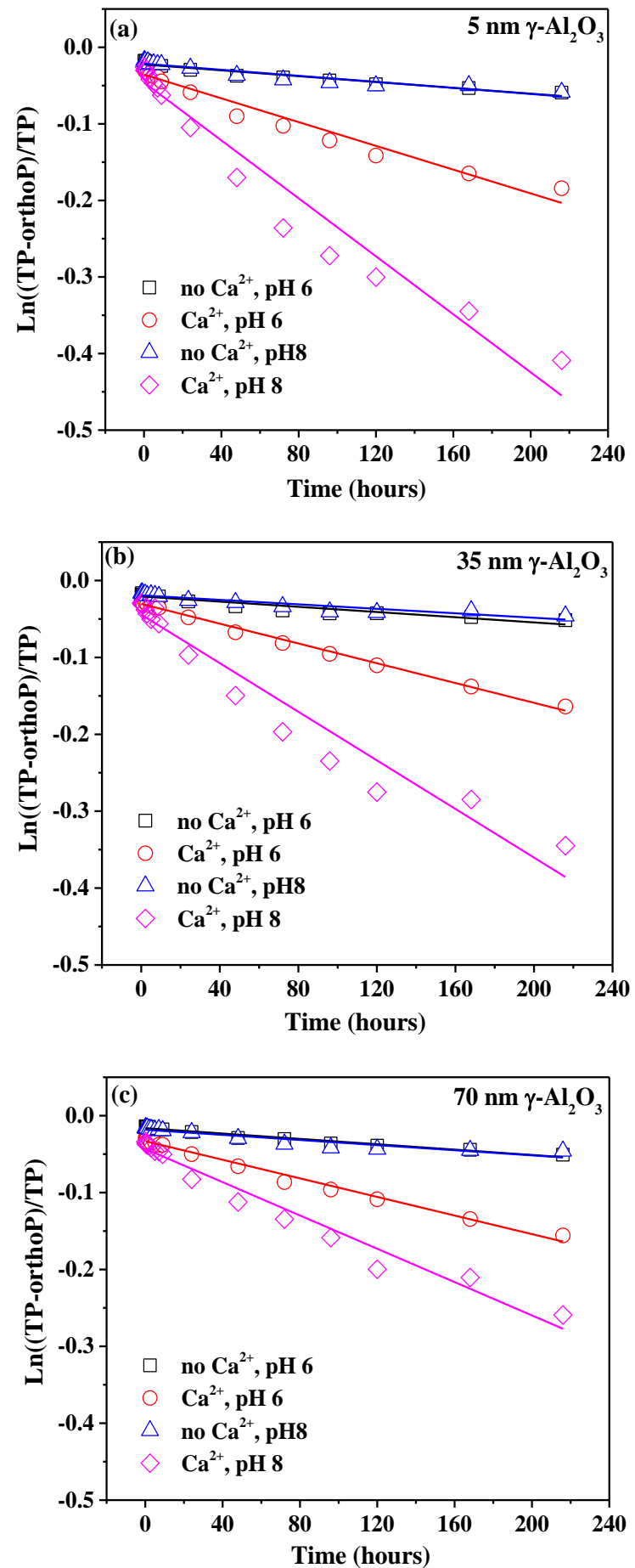

Fig. S5 Hydrolysis kinetics of polyphosphate hydrolysis with (a) $5 \mathrm{~nm}$, (b) $35 \mathrm{~nm}$, and (c) $70 \mathrm{~nm}$ $\gamma-\mathrm{Al}_{2} \mathrm{O}_{3}$ (Experiment Set I). Reaction condition: polyphosphate (2 mM as total $\mathrm{P}$ ), $\gamma-\mathrm{Al}_{2} \mathrm{O}_{3} 0.4 \mathrm{~g} / \mathrm{L}$, pH 6.0 and 8.0, with/without $1 \mathrm{mM} \mathrm{Ca}^{2+}$. Solid lines are the first-order kinetic model fitting results. 


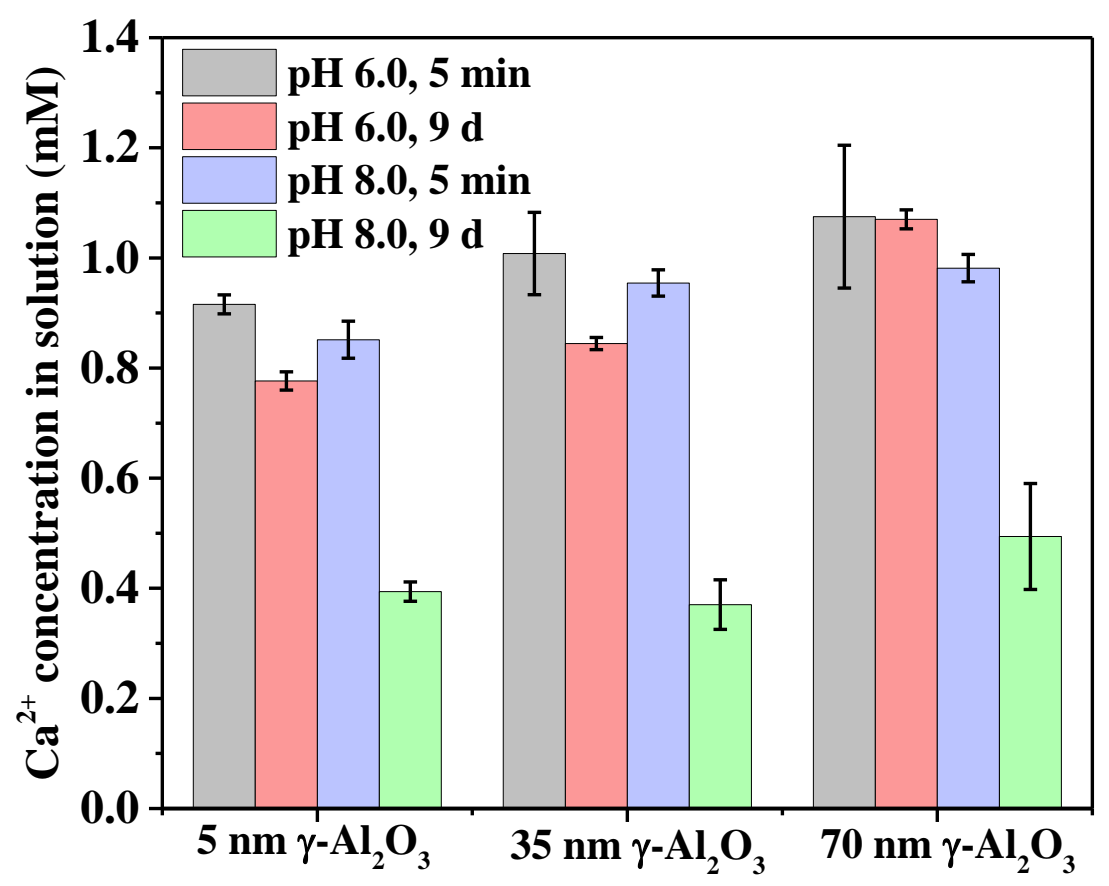

Fig. S6 Final concentration of $\mathrm{Ca}^{2+}$ in solution after polyphosphate reaction with 5, 35, and $70 \mathrm{~nm}$ $\gamma-\mathrm{Al}_{2} \mathrm{O}_{3}$ for $5 \mathrm{~min}$ or $9 \mathrm{~d}$ (Experiment Set I). Reaction condition: polyphosphate ( $2 \mathrm{mM}$ as total $\mathrm{P}$ ), $\gamma-\mathrm{Al}_{2} \mathrm{O}_{3} 0.4 \mathrm{~g} / \mathrm{L}, \mathrm{pH} 6.0$ and 8.0, with/without $1 \mathrm{mM} \mathrm{Ca}^{2+}$. 


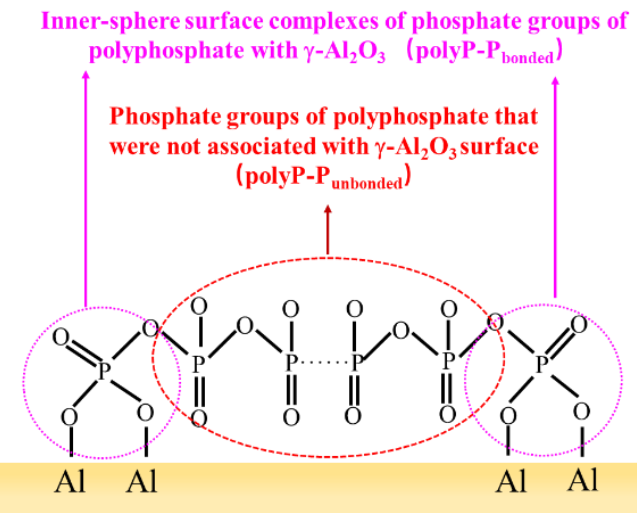

Fig. S7 Schematic illustration for possible coordination structure for polyphosphate at the surface of $\gamma-\mathrm{Al}_{2} \mathrm{O}_{3}$. 

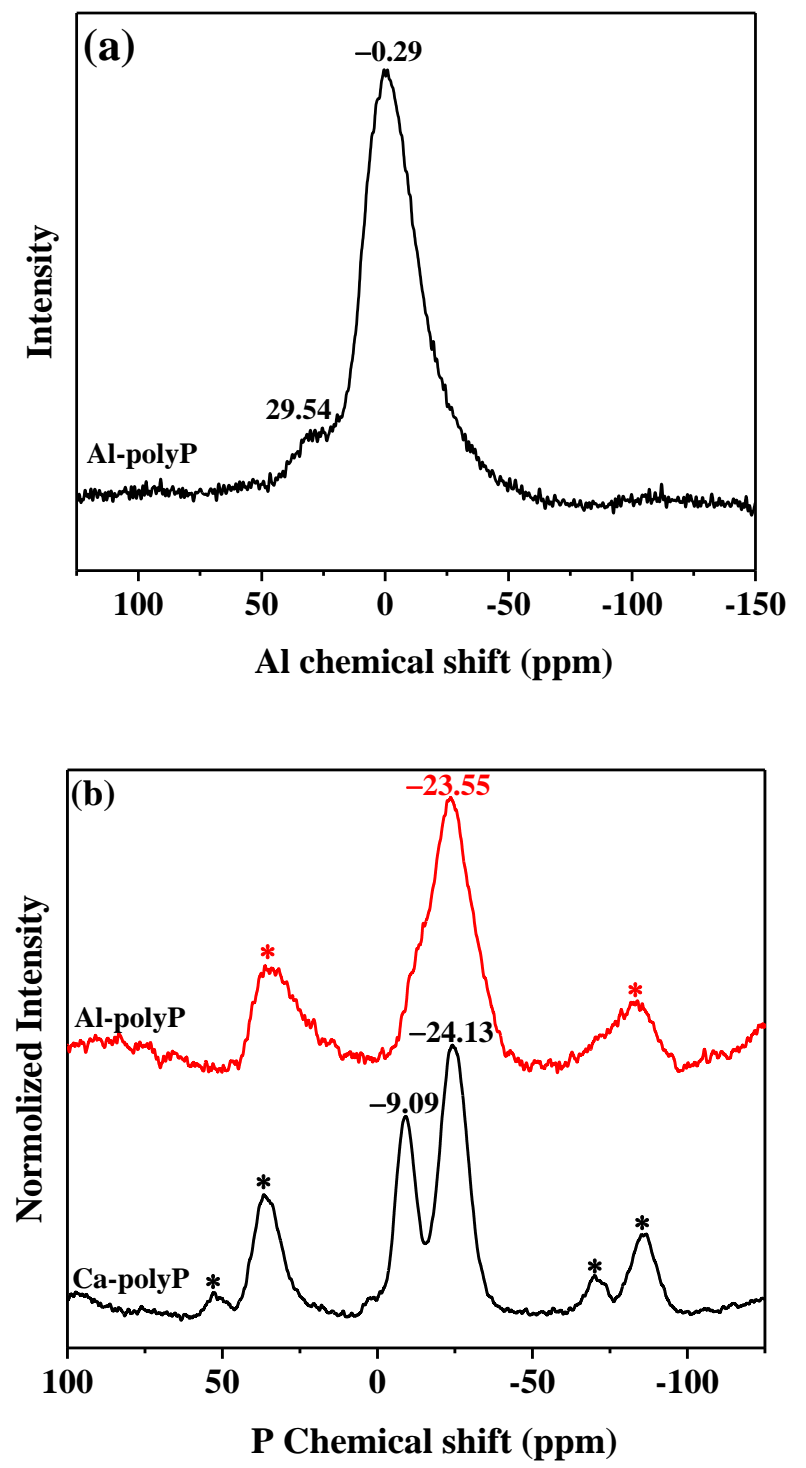

Fig. S8 ${ }^{31} \mathrm{P}$ and ${ }^{27} \mathrm{Al}$ solid-state NMR spectra of synthetic Al-polyphosphate and Ca-polyphosphate compounds. Asterisks denote spinning side bands. 

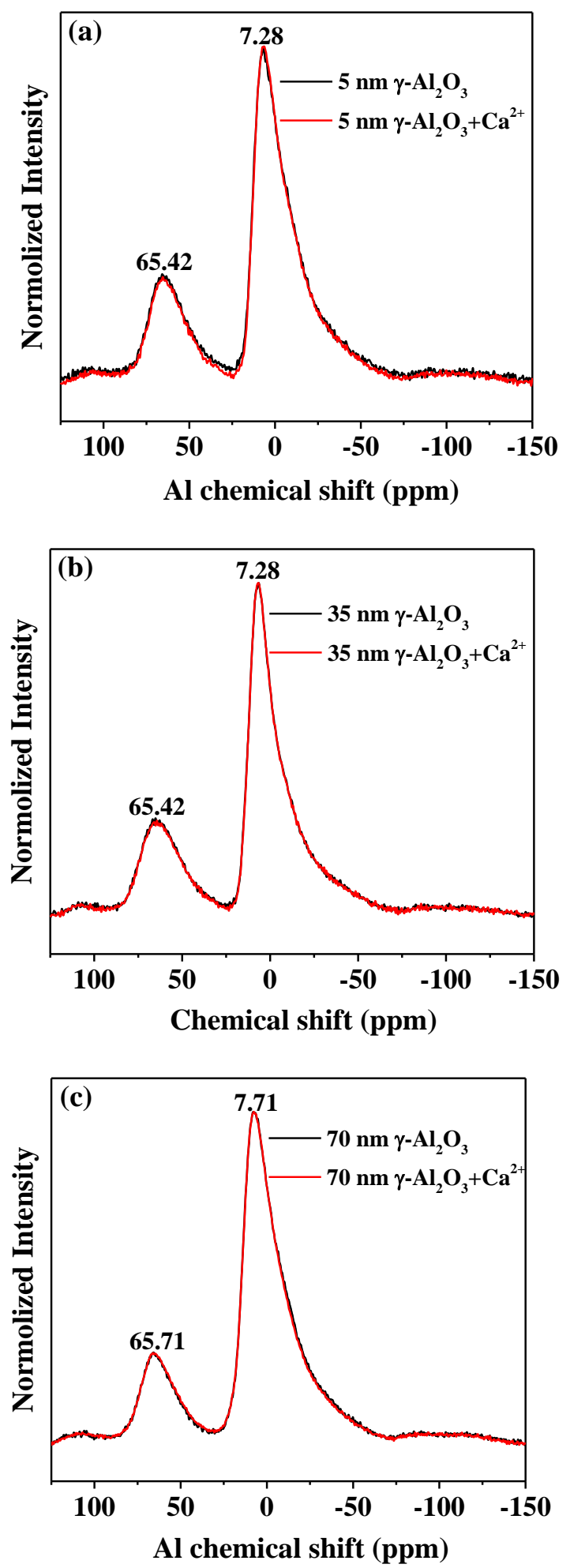

Fig. S9 ${ }^{27} \mathrm{Al}$ solid-state NMR spectra of $\gamma-\mathrm{Al}_{2} \mathrm{O}_{3}$ with $5 \mathrm{~nm}$ (a), $35 \mathrm{~nm}$ (b) and $70 \mathrm{~nm}$ (c) particle size after reaction with polyphosphate (Experiment Set I). Reaction condition: polyphosphate (2 $\mathrm{mM}$ as total $\mathrm{P}$ ), $\gamma-\mathrm{Al}_{2} \mathrm{O}_{3} 0.4 \mathrm{~g} / \mathrm{L}, \mathrm{pH} 6.0$ and 8.0 , with/without $1 \mathrm{mM} \mathrm{Ca}{ }^{2+}, 9 \mathrm{~d}$ reaction time. 

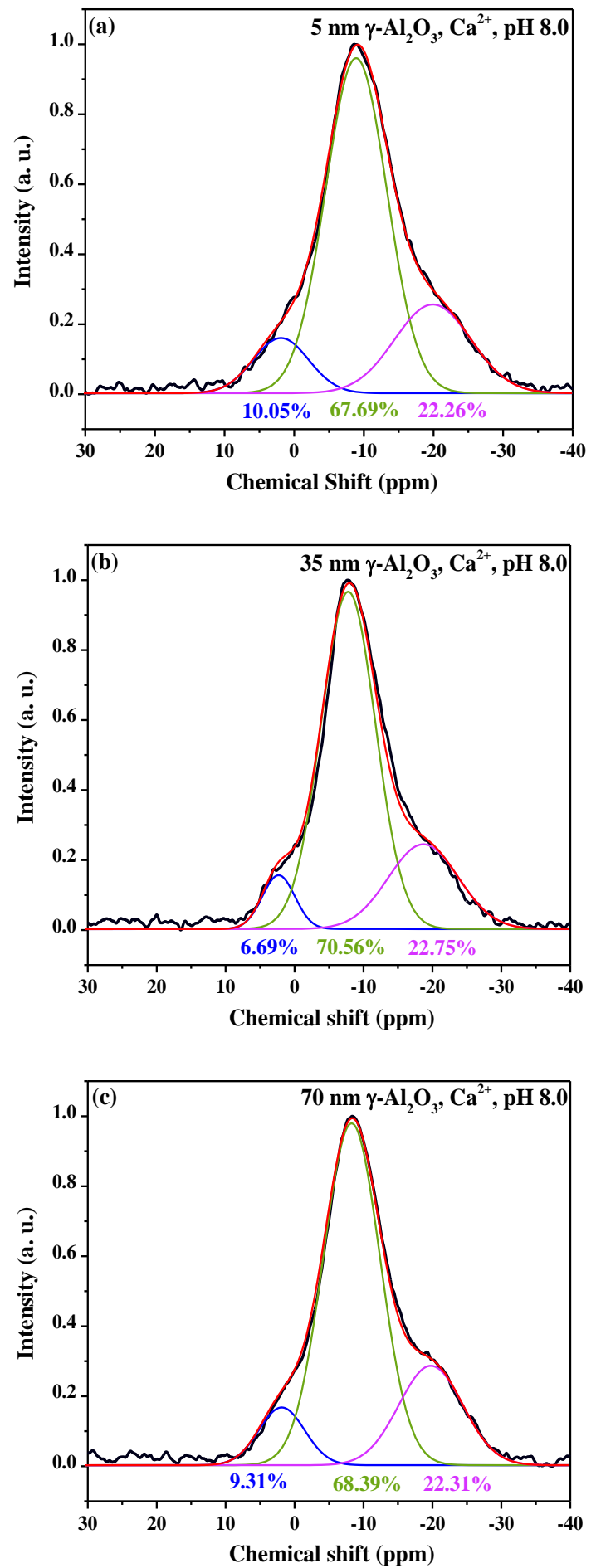

Fig. S10 Deconvolution of single-pulse ${ }^{31} \mathrm{P}$ MAS NMR spectra of the reaction products from polypohosphate with different sized $\gamma-\mathrm{Al}_{2} \mathrm{O}_{3}$ (Experiment Set I). Reaction condition: polyphosphate (2 $\mathrm{mM}$ as total $\mathrm{P}$ ), $\gamma-\mathrm{Al}_{2} \mathrm{O}_{3} 0.4 \mathrm{~g} / \mathrm{L}, \mathrm{pH} 8.0,1 \mathrm{mM} \mathrm{Ca}{ }^{2+}, 9 \mathrm{~d}$. Blue: calcium phosphate precipitates; Green: phosphate groups in polyphosphate that are complexed on mineral

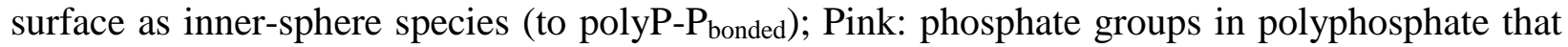
are not directly bonded with mineral surface (to polyP-P $\mathrm{Pnbonded}_{\text {). }}$. 

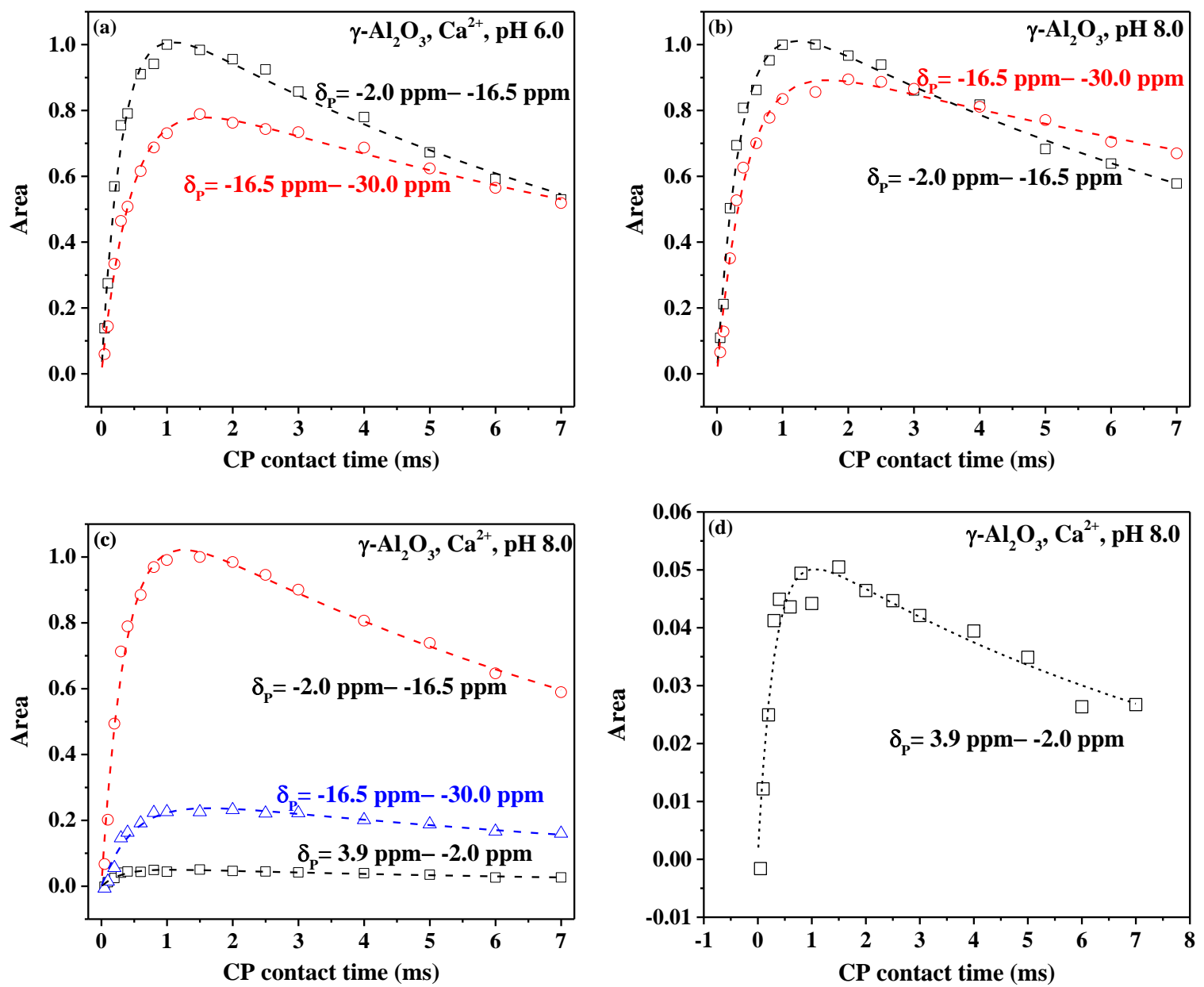

Fig. S11 ${ }^{31} \mathrm{P}\left\{{ }^{1} \mathrm{H}\right\} \mathrm{CP} / \mathrm{MAS}$ kinetics of the two areas (from -2 to -16.5 and from -16.5 to $-30 \mathrm{ppm}$ chemical shifts) for $5 \mathrm{~nm} \gamma-\mathrm{Al}_{2} \mathrm{O}_{3}$ reacting with polyphosphate $(2 \mathrm{mM}$ as total $\mathrm{P})$ with $\mathrm{Ca}^{2+}$ at $\mathrm{pH}$ 6.0 (a), without $\mathrm{Ca}^{2+}$ at $\mathrm{pH} 8.0$ (b), and of the three areas (from 3.9 to -2.0 ; from -2 to -16.5 ; from -16.5 to -30 ) for $5 \mathrm{~nm} \gamma-\mathrm{Al}_{2} \mathrm{O}_{3}$ reacting with polyphosphate with $\mathrm{Ca}^{2+}$ at $\mathrm{pH} 8.0$ (c). (d) is the zoom of (c) for peak area in the range of 3.9 to $-2 \mathrm{ppm}$. Experiments were conducted at a spinning rate of $12 \mathrm{kHz}$ varying contact time from 0.1 to $7 \mathrm{~ms}$. 

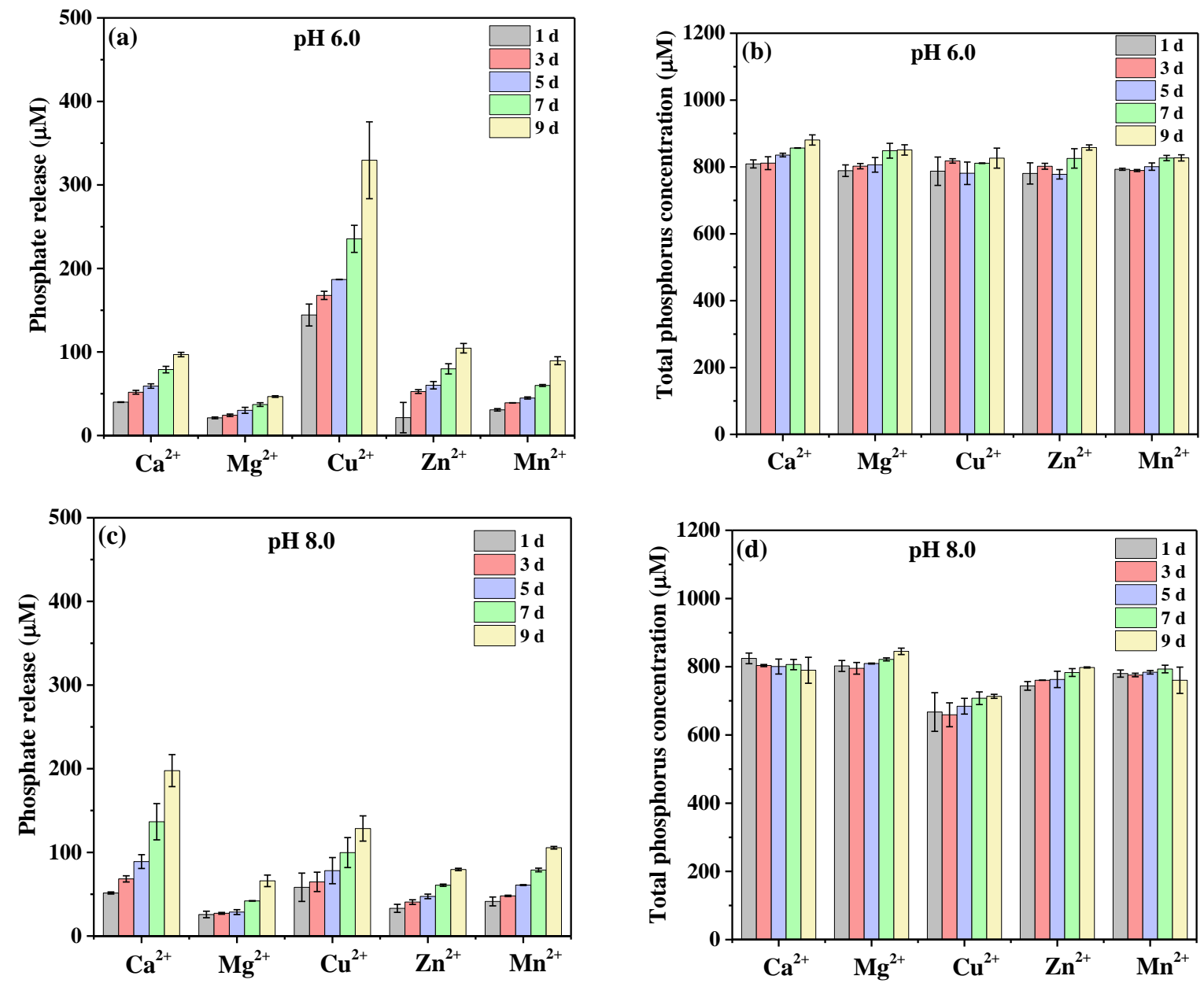

Fig. S12 Effects of different metal cations $(0.5 \mathrm{mM})$ on polyphosphate (1 $\mathrm{mM}$ as total $\mathrm{P})$ hydrolysis (Experiment Set II) by $5 \mathrm{~nm} \gamma-\mathrm{Al}_{2} \mathrm{O}_{3}(0.1 \mathrm{~g} / \mathrm{L})$ at $\mathrm{pH} 6.0(\mathrm{a}, \mathrm{b})$ and 8.0 (c, d). (a) and (c) is the orthophosphate release; (b) and (d) is the total $\mathrm{P}$ concentration in the supernatant. 


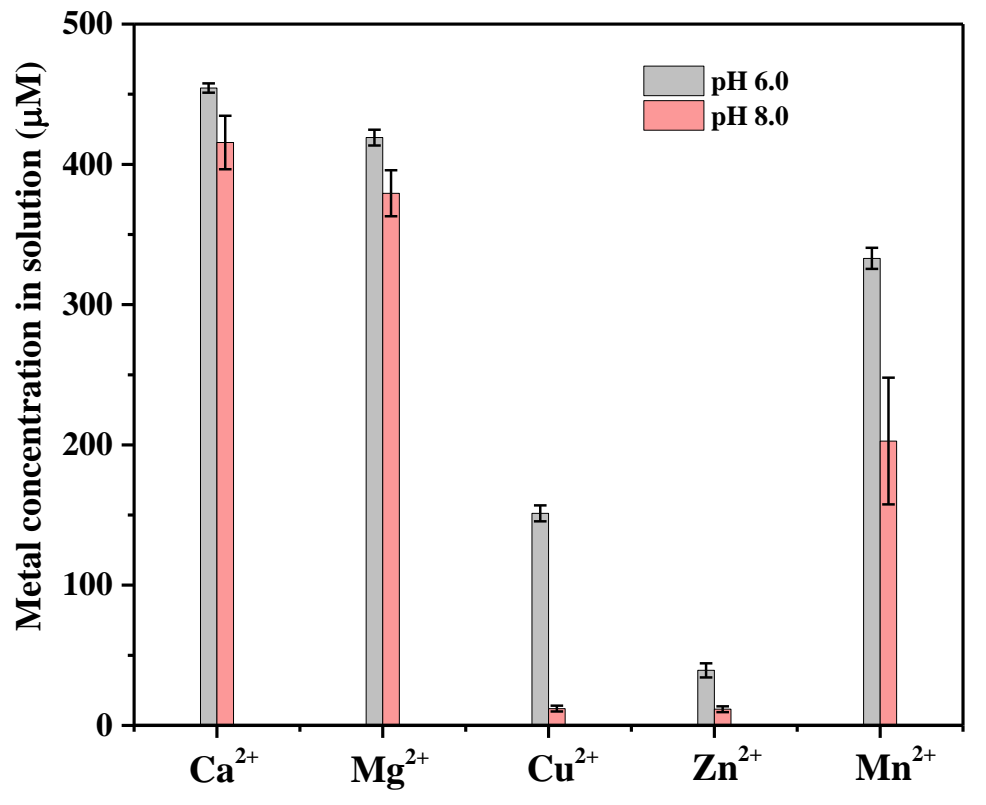

Fig. S13 Metal cation concentration in the supernatant after polyphosphate hydrolysis (Experiment Set II) by $5 \mathrm{~nm} \gamma-\mathrm{Al}_{2} \mathrm{O}_{3}$ for $9 \mathrm{~d}$ at $\mathrm{pH} 6.0$ or 8.0. Initial concentration of metal ions is $0.5 \mathrm{mM}$. 

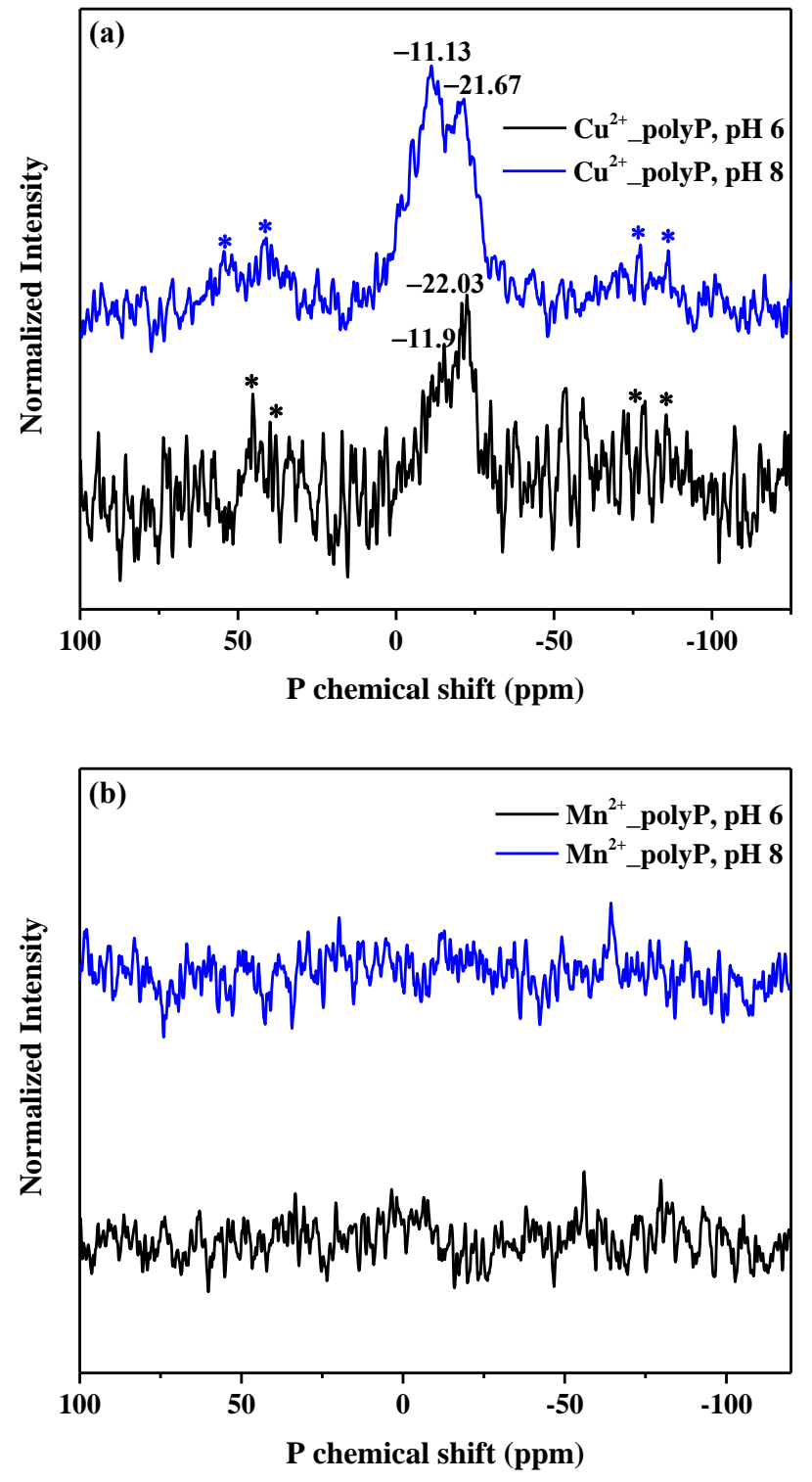

Fig. S14 ${ }^{31} \mathrm{P}$ solid-state NMR spectra of $\gamma-\mathrm{Al}_{2} \mathrm{O}_{3}$ reacting with polyphosphate (Experiment Set II) in the presence of $0.5 \mathrm{mM} \mathrm{Cu}^{2+}$ (a) and $\mathrm{Mn}^{2+}$ (b) at $\mathrm{pH} 6.0$ or 8.0. 

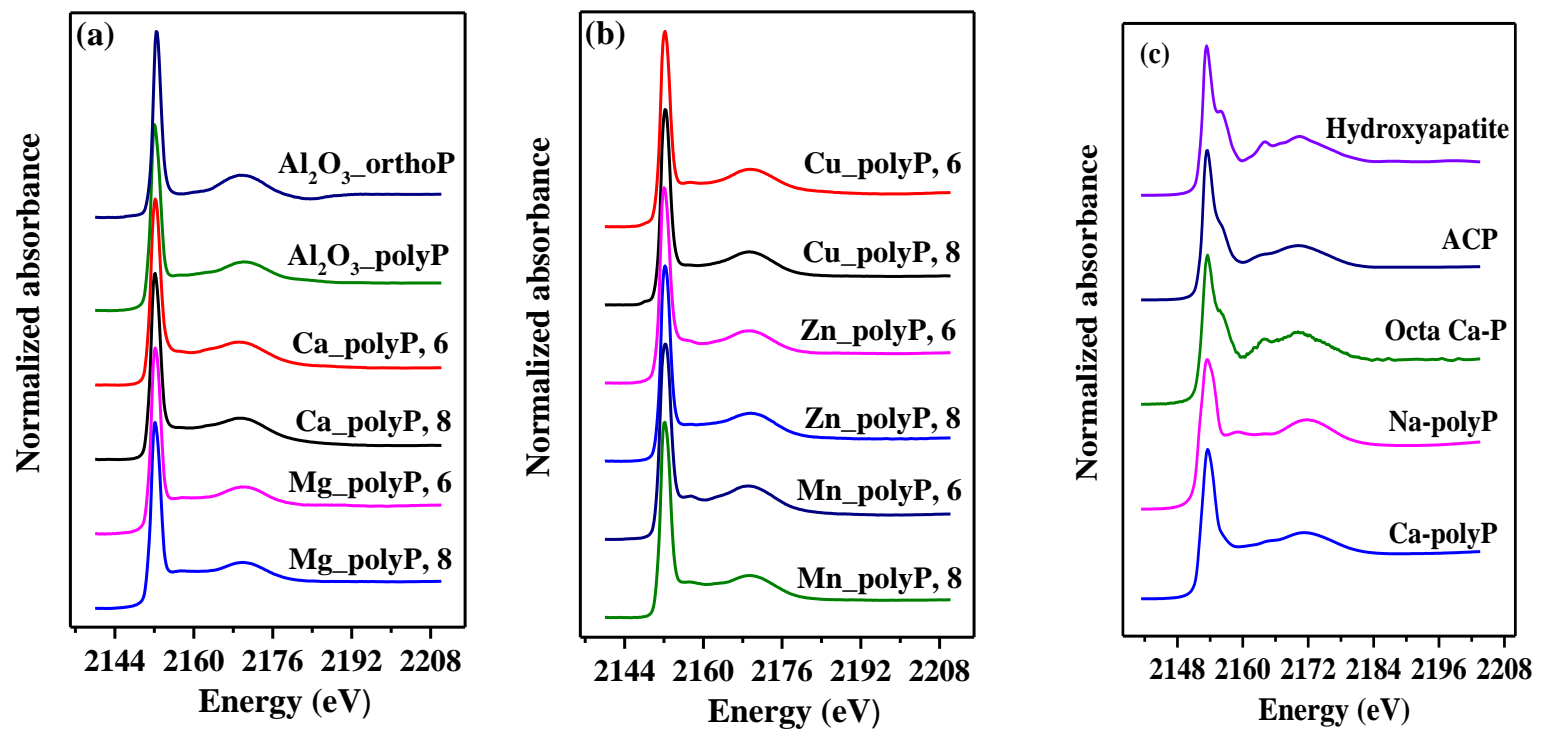

Fig. S15 (a-b) Normalized P K-edge XANES spectra of the reaction products from polyphosphate hydrolysis by $\gamma-\mathrm{Al}_{2} \mathrm{O}_{3}$ (Experiment Set II) with $0.5 \mathrm{mM}$ metal ions at $\mathrm{pH} 6.0$ or 8.0. (c) Normalized P K-edge XANES spectra of phosphate reference compounds used for linear combination fitting of reaction products.

Sample labels: $\mathrm{Al}_{2} \mathrm{O}_{3}$ polyP $\left(\mathrm{Al}_{2} \mathrm{O}_{3}\right.$-adsorbed polyphosphate); $\mathrm{Al}_{2} \mathrm{O}_{3}$ orthoP $\left(\mathrm{Al}_{2} \mathrm{O}_{3}\right.$-adsorbed orthophosphate); $\mathrm{Ca} / \mathrm{Mg} / \mathrm{Cu} / \mathrm{Zn} / \mathrm{Mn} \_$polyP, 6 or 8 refer to polyP hydrolysis experiments conducted in the presence of metal cations $\left(\mathrm{Ca}^{2+}, \mathrm{Mg}^{2+}, \mathrm{Cu}^{2+}, \mathrm{Zn}^{2+}\right.$, or $\left.\mathrm{Mn}^{2+}\right)$ at $\mathrm{pH} 6.0$ or 8.0; sodium polyphosphate salt (Na-polyP), synthesized calcium polyphosphate granules (Ca-polyP), amorphous calcium phosphate (ACP), octacalcium phosphate (octa Ca-P). 

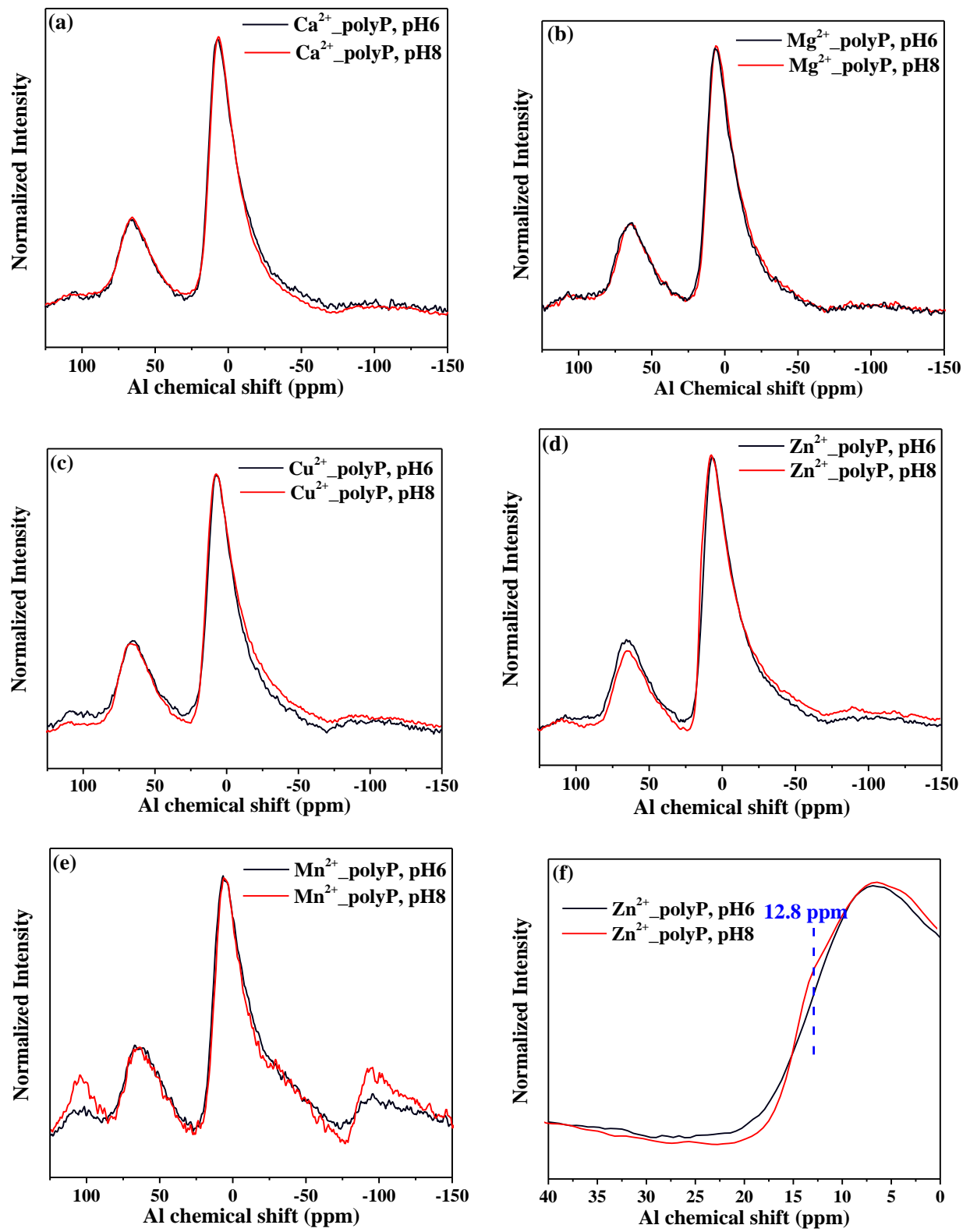

Fig. S16 ${ }^{27} \mathrm{Al}$ solid-state NMR spectra of the solid products after polyphosphate reaction with 5 $\mathrm{nm} \gamma-\mathrm{Al}_{2} \mathrm{O}_{3}$ in the presence of $0.5 \mathrm{mM}$ metal ions $\left(\mathrm{Ca}^{2+}, \mathrm{a} ; \mathrm{Mg}^{2+}, \mathrm{b} ; \mathrm{Cu}^{2+}, \mathrm{c} ; \mathrm{Zn}^{2+}, \mathrm{d} ; \mathrm{Mn}^{2+}, \mathrm{e}\right)$ (Experiment Set II) at pH 6.0 or 8.0 after $9 \mathrm{~d}$. (f) is the zoom image of Fig. S14d in chemical shift range of $40-0 \mathrm{ppm}$. 


\section{References}

1. Yan, Y.; Luuk K. K.; Li, W.; Zheng, A.; Yang, J.; Liu, F.; Feng. X. Size-dependent sorption of myo-inositol hexakisphosphate and orthophosphate on nano- $\gamma-\mathrm{Al}_{2} \mathrm{O}_{3}$. J. Colloid Interface Sci. 2015, 451, 85-92.

2. Li, W.; Feng, X.; Yan, Y.; Sparks, D. L.; Phillips, B. L. Solid-state NMR spectroscopic study of phosphate sorption mechanisms on aluminum (hydr)oxides. Environ. Sci. Technol. 2013, 47, 8308-8315.

3. Yan, Y. P.; Liu, F.; Li, W.; Liu, F.; Feng, X. H.; Sparks, D. L. Sorption and desorption characteristics of organic phosphates of different structures on aluminium (oxyhydr)oxides. Eur. J. Soil Sci. 2014, 65, 308-317.

4. Chang, H.S.; Korshin, G.V.; Wang, Z.; Zachara, J.M. Adsorption of uranyl on gibbsite: A timeresolved laser-induced fluorescence spectroscopy study. Environ. Sci. Technol. 2006, 40, 1244-1249.

5. Roelofs, F.; Vogelsberger, W. Dissolution kinetics of nanodispersed $\gamma$-alumina in aqueous solution at different $\mathrm{pH}$ : Unusual kinetic size effect and formation of a new phase. J. Colloid Interface Sci. 2006, 303, 450-459.

6. Fang, W.; Sheng, G.; Wang, L.; Ye, X.; Yu, H. Quantitative evaluation of noncovalent interactions between polyphosphate and dissolved humic acids in aqueous conditions. Environ. Pollut. 2015, 207, 123-129.

7. Kolodziejski, W.; Klinowski, J. Kinetics of cross-polarization in solid-state NMR: A guide for chemists. Chem. Rev. 2002, 102, 613-628.

8. Huang R.; Tang Y. Speciation dynamics of phosphorus during pyrolysis and hydrothermal treatment of sewage sludge. Environ. Sci. Technol. 2015, 49, 14466-14474.

9. Ravel, A.; Newville, M. ATHENA, ARTEMIS, HEPHAESTUS: Data analysis for X-ray absorption spectroscopy using IFEFFIT. J. Synchrotron Radiat. 2005, 12, 537-541. 